\title{
Safety, efficacy, and patient acceptability of rifaximin for hepatic encephalopathy
}

\author{
This article was published in the following Dove Press journal: \\ Patient Preference and Adherence \\ 18 March 2014 \\ Number of times this article has been viewed
}

\author{
Nina Kimer ${ }^{1}$ \\ Aleksander Krag ${ }^{2}$ \\ Lise L Gluud' \\ 'Gastrounit, Medical Division, \\ Copenhagen University Hospital \\ Hvidovre, Hvidovre, Denmark; \\ ${ }^{2}$ Department of Gastroenterology, \\ Odense University Hospital, \\ University of Southern Denmark, \\ Odense, Denmark
}

\begin{abstract}
Hepatic encephalopathy is a complex disease entity ranging from mild cognitive dysfunction to deep coma. Traditionally, treatment has focused on a reduction of ammonia through a reduced production, absorption, or clearance. Rifaximin is a nonabsorbable antibiotic, which reduces the production of ammonia by gut bacteria and, to some extent, other toxic derivatives from the gut. Clinical trials show that these effects improve episodes of hepatic encephalopathy. A large randomized trial found that rifaximin prevents recurrent episodes of hepatic encephalopathy. Most patients were treated concurrently with lactulose. Trials have varied greatly in design, outcomes, and duration of treatment regimes. Although a number of retrospective studies have indicated that long-term treatment with rifaximin is safe and possibly beneficial, high quality trials are needed to further clarify efficacy and safety of long-term treatment with rifaximin and evaluate effects of combination therapy with lactulose and branched-chain amino acids for patients with liver cirrhosis and hepatic encephalopathy.
\end{abstract}

Keywords: prevention, lactulose, liver cirrhosis

\section{Introduction}

Hepatic encephalopathy (HE) is a neuropsychiatric complication to liver failure, ranging from mild confusion to severe coma. Patients with cirrhosis and ascites have a $15 \%$ risk of developing $\mathrm{HE}$ within 1 year. Once $\mathrm{HE}$ is developed, the 1-year mortality exceeds $60 \% .^{1}$ Hospitalizations are common and present a considerable challenge to the patient, the concerned family, and the health care system. ${ }^{2,3}$ The high morbidity and mortality combined with the costs underline the importance of effective treatment and prevention of $\mathrm{HE}$.

HE is a complex disease that may be associated with acute liver failure, portal-systemic bypass, or cirrhosis and portal hypertension. ${ }^{4}$ Based on the clinical characteristics, $\mathrm{HE}$ can be classed as minimal, recurrent, or overt HE. Minimal HE presents with minor neurological and cognitive deficits that require advanced neuropsychological testing to diagnose. Overt HE presents with confusion and loss of consciousness, which can be episodic or persistent. ${ }^{5}$ A number of scoring systems are developed to grade the severity of overt HE. The West Haven criteria are often used and class HE on a scale from 0 to 4. A more recent guideline, which underlines the difficulty of diagnosing minimal signs of HE, recommends the term covert HE, which covers both minimal HE and HE with minor clinically discernible signs (corresponding to West Haven grade 1). ${ }^{6}$

The presumed pathology of HE includes a derangement in ammonium metabolism due to increased bacterial ammonia production in the gut and possibly a decreased ammonia clearance from the kidneys. ${ }^{7}$ Hyperammonemia induces encephalopathy
Correspondence: Nina Kimer Department of Gastroenterology, Copenhagen University Hospital Hvidovre, Kettegaard Alle 30, 2650 Hvidovre, Denmark Email nina.kimer@regionh.dk 
by promoting cerebral edema, modulating the blood-brain barrier, decreasing blood flow, or modulating neuroinhibition. A number of treatments therefore aim at eliminating the ammonia producing bacteria from the gut. ${ }^{8-10}$ The recommended treatments include the nonabsorbable disaccharides lactulose and lactitol, which have several potential mechanisms of action. The beneficial effects include reduced generation of ammonia from gut bacteria and an increased intestinal transit time. Branched-chain amino acids are also recommended for the treatment of HE. These amino acids include leucine, isoleucine, and valine, which are believed to correct the ratio between aromatic and branched-chain amino acids, resulting in a decreased formation of false neurotransmitters. Branched-chain amino acids also improve nitrogen metabolism and reduce malnutrition.

Rifaximin is a nonabsorbable antibiotic with antimicrobial effects on a broad spectrum of gut bacteria. ${ }^{11,12}$ Rifaximin has little effect on the normal gut flora, and resistance is infrequent. ${ }^{13}$

In the last three decades, several trials have investigated the efficacy of rifaximin in comparison with placebo, or no intervention, or to other active treatments such as disaccharides and other antibiotics. ${ }^{14-19}$ Trials are diverse in size, outcome measures, and patient inclusion criteria, which makes a thorough evaluation of the drug efficacy difficult. In 2010, the US Food and Drug Administration (FDA) approved the use of rifaximin as prophylaxis for episodic or recurrent $\mathrm{HE}$ following the publication of a large randomized trial stating a significant decrease in hospitalization rates among patients treated with rifaximin for 6 months or more. ${ }^{15}$ Rifaximin is also used with the same indication in several European countries. Unfortunately, rifaximin remains expensive, with an average wholesale price of US\$1,586 for 1 month of treatment. The average wholesale price for lactulose is about US\$79 per month depending on the necessary dose..$^{20}$ Previous studies have suggested a cost-effective benefit of rifaximin compared with disaccharides, ${ }^{21}$ but patient acceptability and adherence to treatment remains unclear. In this review, we will assess the safety, efficacy, and patient acceptability of maintenance therapy of HE.

\section{Assessment of the available literature}

We conducted a systematic search of the potentially relevant available literature identified through searches in MEDLINE ${ }^{\circledR}$, Web of Science ${ }^{\mathrm{TM}}$, and Embase ${ }^{\circledR}$. The search terms "rifaximin AND hepatic encephalopathy," "rifaximin AND hepatic encephalopathy AND cost," and "long-term rifaximin
AND hepatic encephalopathy" revealed 15 randomized trials (reported in 16 records), two prospective clinical trials, eight retrospective trials and decision analyses, and 25 relevant reviews and meta-analyses. Manual searches of bibliographies and abstracts from the American Association for the Study of Liver Diseases and the European Association for the Study of the Liver within the last 5 years (2008-2013) identified another eight randomized trials, three prospective studies, and two retrospective analyses (Table 1).

The 23 randomized trials were published between 1984 and 2013. Outcomes were diverse, and patient cohorts highly heterogeneous. Seven randomized trials reported no clinical outcomes or evaluated rifaximin administered for less than 7 days. ${ }^{17,22-28}$ The remaining trials evaluated longterm treatment or prevention of HE with rifaximin. Twelve randomized trials assessed the effect of rifaximin on overt HE. ${ }^{16,18,19,29-37}$ Two trials assessed the effect of rifaximin on minimal $\mathrm{HE},{ }^{14,38}$ and one trial (described in two records) assessed the prophylactic effect of rifaximin on recurrent HE. ${ }^{15,39}$

Five prospective cohort studies (described in three full-paper articles ${ }^{40-42}$ and three abstracts ${ }^{43-45}$ ) assessed complications and recurrence of $\mathrm{HE}$ in patients receiving rifaximin for 6 months up to 5 years.

Six retrospective studies evaluated the effects of rifaximin on the number of hospitalizations, rates of infections, and treatment patterns in patients with overt HE. ${ }^{2,46-50}$ Three papers reported analyses that assessed the cost-effectiveness in the treatment of $\mathrm{HE}$ with long-term rifaximin. ${ }^{51-53}$

\section{Clinical efficacy of rifaximin Prevention of recurrent $\mathrm{HE}$}

A large randomized trial from 2010 with 299 patients concluded that rifaximin reduces the risk of new episodes of $\mathrm{HE}$ and decreases hospitalizations due to $\mathrm{HE}$ in patients with previous episodes of overt HE. ${ }^{15}$ Included patients were nonresponders to the nonabsorbable disaccharide lactulose. The mean duration of treatment was 130 days. The overall results showed a number needed to treat of four patients. Accordingly, to prevent one episode of overt HE, four patients needed treatment with rifaximin for 130 days. Long-term treatment with rifaximin was assessed in an openlabel extension of this trial. The extension trial also found a reduction in hospitalizations and episodes of HE. ${ }^{43,45}$ In accordance with these findings, a prospective cohort study including 69 patients with previous HE found that long-term treatment with rifaximin decreases portal hypertension and reduces the risk of complications to cirrhosis. ${ }^{42} \mathrm{~A}$ prospective 
Table I Overview of the literature

\begin{tabular}{|c|c|c|c|}
\hline Study & $\begin{array}{l}\text { Number of } \\
\text { patients }\end{array}$ & Primary outcomes & Significant trial results \\
\hline \multicolumn{4}{|c|}{ Randomized trials } \\
\hline Eftimiadi et $\mathrm{al}^{23}$ & 20 & Gut flora & No statistical comparison reported \\
\hline De Marco et $\mathrm{al}^{17}$ & 32 & HE grade, s-ammonia, and blood biochemistry & No significant difference among treatment groups \\
\hline Testa et $\mathrm{a}^{26}$ & 20 & s-ammonia, NCT, and gut flora & No significant difference among treatment groups \\
\hline Riggio et $\mathrm{a}^{24}$ & 75 & Breakthrough of HE; s-ammonia & No significant difference among treatment groups \\
\hline Song et $\mathrm{a}^{25, \mathrm{a}}$ & 64 & Mental status and s-ammonia & No significant difference among treatment groups \\
\hline Williams et $\mathrm{a}^{28, \mathrm{~b}}$ & 54 & PSE index, EEG, and s-ammonia & No significant difference among treatment groups \\
\hline Di Piazza et $\mathrm{al}^{22}$ & 14 & Asterixis; trail-making test & No significant difference among treatment groups \\
\hline Venturini et $\mathrm{al}^{27}$ & 18 & Benzodiazepine-like compounds & $\begin{array}{l}\text { Benzidiazepine-like compounds lowered in } \\
\text { rifaximin group }\end{array}$ \\
\hline Festi et $\mathrm{a}^{31}$ & 59 & Asterixis, s-ammonia, and EEG & No significant difference among treatment groups \\
\hline Miglio et $\mathrm{a}^{34}$ & 60 & s-ammonia, trans-aminases, and trail-making test & Improved trail-making test in rifaximin group \\
\hline Parini et al ${ }^{19}$ & 30 & $\mathrm{HE}$ grade and s-ammonia & No significant difference among treatment groups \\
\hline Pedretti et $\mathrm{a}^{36}$ & 30 & $\begin{array}{l}\text { Neuropsychometric tests, EEG, PSE index, } \\
\text { and s-ammonia }\end{array}$ & Lower s-ammonia in the rifaximin group \\
\hline Fera et $\mathrm{al}^{30}$ & 40 & $\begin{array}{l}\text { Mental state, A-cancellation-test (neuropsychometric } \\
\text { test), trail-making test, EEG irregularities, and } \\
\text { s-ammonia }\end{array}$ & $\begin{array}{l}\text { Mental state improved in rifaximin group, trail- } \\
\text { making test improved in lactulose group }\end{array}$ \\
\hline Paik et $\mathrm{al}^{35}$ & 54 & HE index, s-ammonia, and NCT & No significant difference among treatment groups \\
\hline Massa et $\mathrm{al}^{33}$ & 40 & $\begin{array}{l}\text { Mental state, a-cancellation test, trail-making test, } \\
\text { and s-ammonia }\end{array}$ & $\begin{array}{l}\text { Improvement in mental status and trail-making } \\
\text { test in the rifaximin group }\end{array}$ \\
\hline $\begin{array}{l}\text { Bucci and } \\
\text { Palmieri' }\end{array}$ & 58 & Mental state, a-cancellation test, EEG, and PSE index & $\begin{array}{l}\text { Improvement in EEG irregularities and } \\
\text { a-cancellation test in rifaximin group. }\end{array}$ \\
\hline Loguercio et a $\left.\right|^{32}$ & 26 & Mental state, asterixis, NCT, s-ammonia & $\begin{array}{l}\text { Decrease in s-ammonia level in the } \\
\text { rifaximin+lactitol group }\end{array}$ \\
\hline Mas et $\mathrm{al}^{18}$ & 103 & s-ammonia, NCT, EEG, and PSE index & No significant difference among treatment groups \\
\hline Bass et $\mathrm{a}^{29, \mathrm{a}}$ & 93 & $\begin{array}{l}\text { s-ammonia, NCT, mental state, PSE index, } \\
\text { and asterixis }\end{array}$ & Improvement in asterixis in rifaximin group \\
\hline Bass et $\mathrm{al}^{15}$ & 299 & HE episodes and hospitalizations & $\begin{array}{l}\text { Decreased number of recurrent episodes of } \mathrm{HE} \\
\text { and hospitalization rates in rifaximin group }\end{array}$ \\
\hline Sidhu et $\mathrm{a}^{38}$ & 94 & HRQL, SIP score, and NCT & Decrease in SIP score in rifaximin group \\
\hline Bajaj et al ${ }^{14}$ & 42 & $\begin{array}{l}\text { Biochemistry, neuropsychometric testing, driving } \\
\text { capacity, and sickness impact profile }\end{array}$ & $\begin{array}{l}\text { Improvement in sickness impact profile and } \\
\text { fewer driving errors in rifaximin group }\end{array}$ \\
\hline Sharma et $\mathrm{al}^{37}$ & 120 & Mortality, recovery of $\mathrm{HE}$, and hospitalization & $\begin{array}{l}\text { Lower mortality and hospitalization duration in } \\
\text { rifaximin group }\end{array}$ \\
\hline \multicolumn{4}{|c|}{ Prospective trials } \\
\hline $\begin{array}{l}\text { Vlachogiannakos } \\
\text { et al }{ }^{42}\end{array}$ & 69 & $\begin{array}{l}\text { Prevention of HE, portal hypertension, and } \\
\text { complications to cirrhosis }\end{array}$ & $\begin{array}{l}\text { Lower risk of developing HE and complications } \\
\text { to cirrhosis in rifaximin group }\end{array}$ \\
\hline Irima et $\mathrm{al}^{40, \mathrm{c}}$ & 78 & Prevention of recurrent HE; hospitalizations & No significant difference among treatment groups \\
\hline Tandon et $\mathrm{al}^{41}$ & 115 & $\begin{array}{l}\text { Antibiotic resistant infections and antibiotic } \\
\text { exposure }\end{array}$ & No data on rifaximin treatment alone \\
\hline Sanyal et $\mathrm{al}^{45, \ddagger, \mathrm{a}}$ & 392 & Infection rates and antibiotic use & No statistical comparison reported \\
\hline Bajaj et $\mathrm{al}^{43, \neq, \mathrm{a}}$ & 82 & Incidence of breakthrough HE & No statistical comparison reported \\
\hline O'Leary et al $\left.\right|^{44}$ & 175 & Recurrent infections and use of antibiotics & $\begin{array}{l}\text { Higher rates of rifaximin use in patients with } \\
\text { recurrent infections }\end{array}$ \\
\hline \multicolumn{4}{|c|}{ Retrospective analyses } \\
\hline $\begin{array}{l}\text { Leevy and } \\
\text { Phillips }^{2}\end{array}$ & $145^{\#}$ & $\begin{array}{l}\text { Hospitalization rates, HE grade, asterixis, and } \\
\text { adverse events }\end{array}$ & $\begin{array}{l}\text { Decreased hospitalization rates, decreased } \\
\text { asterixis, and fewer patients with } \mathrm{HE} \\
\text { grade } 3-4 \text { during rifaximin treatment }\end{array}$ \\
\hline Neff et $\mathrm{al}^{49}$ & 39 & $\begin{array}{l}\text { Hospitalization rates, economic data, and } \\
\text { MELD score }\end{array}$ & $\begin{array}{l}\text { No statistical comparison between groups } \\
\text { reported }\end{array}$ \\
\hline $\begin{array}{l}\text { Mantry and } \\
\text { Munsaff6 }\end{array}$ & 65 & Hospitalizations & $\begin{array}{l}\text { Reduced risk of hospitalization during rifaximin } \\
\text { treatment }\end{array}$ \\
\hline Neff et al ${ }^{47}$ & 203 & Prevention of HE; MELD score & No comparison between groups performed \\
\hline Neff ${ }^{50}$ & 45,480 & Treatment patterns and use of rifaximin & No statistical comparison between groups reported \\
\hline Neff et al $\left.\right|^{48}$ & 211 & Development of Clostridium difficile infections & $\begin{array}{l}\text { No control group; no Clostridium difficile } \\
\text { infections }\end{array}$ \\
\hline
\end{tabular}

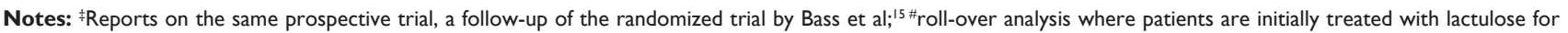
6 months followed by rifaximin for 6 months; apublished as abstracts; bdose-finding trial, no control group; 'only abstract in English.

Abbreviations: EEG, electroencephalography; HE, hepatic encephalopathy; HRQL, health-related quality of life; MELD, Model of End Stage Liver Disease; NCT, number connection test; PSE, portal systemic encephalopathy; SIP, sickness impact profile. 
study of 78 patients recovering from $\mathrm{HE}$ found that rifaximin is superior to lactulose in reducing HE-related hospitalization, but that lactulose was equally effective in preventing new episodes of HE. ${ }^{40}$ Reduced hospitalization rates and decreased recurrence of HE were also found in four retrospective analyses comprising a total of 452 patients on maintenance therapy. $2,46,47,49$

\section{Treatment of minimal HE}

Two randomized trials comprising a total of 136 patients assessed the effect of rifaximin versus placebo on minimal HE. ${ }^{14,38}$ The primary endpoint in one trial was driving performance, whereas the other assessed reversal of minimal HE. Duration of treatment was 8 weeks. None of the included patients in these trials had previous episodes of HE. Only three patients developed overt HE during the study period (two patients in the placebo group and one patient in the rifaximin group). Data are inconclusive on whether rifaximin can prevent overt $\mathrm{HE}$ in patients with minimal HE. Both trials found some evidence of improved manifestations of minimal HE. The overall results were promising, but not conclusive.

\section{Treatment of overt HE}

Eighteen randomized trials have assessed the effect of rifaximin on overt HE. One trial was a dose-finding study, ${ }^{28}$ one trial included patients after transjugular intrahepatic portosystemic shunt, ${ }^{24}$ and one trial was a crossover design. ${ }^{22}$ Sixteen trials included a control group of placebo, disaccharides, or other antibiotics. ${ }^{16-19,23,25,26,29-36,54}$ Treatment duration lasted from 5 to 21 days. Trials are characterized in Table 1. A thorough evaluation of the quality, relevance, and clinical efficiency of these studies lies beyond the scope of this paper.

\section{Safety of rifaximin treatment}

Randomized trials have focused on rifaximin for the treatment of acute overt HE. The trials found that the safety of rifaximin was equal to that of comparative treatments. Few side effects such as nausea, diarrhea, vomiting, abdominal discomfort, and flatulence were reported in the rifaximin group. The risk of these adverse events was lower in the rifaximin group compared with the lactulose group. ${ }^{16,33}$ Safety assessment is summarized in Table 2.

The risk of adverse events was similar to that of placebo and did not increase with prolonged treatment up to 6 months. ${ }^{14,15}$

In a prospective cohort study, the effect of rifaximin on complications to liver cirrhosis was assessed during a follow-up period of 5 years. ${ }^{41}$ The study found that complications such as hepatorenal syndrome, spontaneous bacterial peritonitis, and HE was significantly reduced

Table 2 Safety assessment of rifaximin

\begin{tabular}{|c|c|c|c|c|c|c|}
\hline \multirow[t]{2}{*}{ Study } & \multicolumn{3}{|c|}{ Adverse events - rifaximin } & \multicolumn{3}{|c|}{ Adverse events - control } \\
\hline & Number of patients & Mild & Severe & Number of patients & Mild & Severe \\
\hline \multicolumn{7}{|l|}{ Randomized trials } \\
\hline Bucci and Palmieri' ${ }^{16}$ & 30 & 9 & 0 & 28 & 65 & 0 \\
\hline Loguercio et $\mathrm{al}^{32}$ & 27 & 0 & 0 & 13 & 0 & 0 \\
\hline Massa et $\mathrm{al}^{33}$ & 20 & 0 & 0 & 20 & 28 & 0 \\
\hline Mas et $\mathrm{al}^{18}$ & 50 & 3 & 3 & 53 & 2 & 3 \\
\hline Paik et $\mathrm{al}^{35}$ & 32 & I & 0 & 22 & I & 0 \\
\hline De Marco et al ${ }^{17}$ & 18 & 0 & 0 & 14 & 0 & 0 \\
\hline Parini et al ${ }^{19}$ & 15 & 0 & 0 & 15 & 0 & 0 \\
\hline Pedretti et $\mathrm{al}^{36}$ & 15 & 0 & 0 & 15 & 9 & 0 \\
\hline Bajaj et al $^{14}$ & 21 & 20 & 0 & 21 & 29 & 0 \\
\hline Bass et $\mathrm{al}^{29}$ & 48 & NA & 6 & 45 & NA & 6 \\
\hline Bass et $\mathrm{al}^{15}$ & 140 & 406 & 44 & 159 & 417 & 44 \\
\hline Sidhu et $\mathrm{a}^{38}$ & 49 & 12 & 0 & 45 & 0 & 0 \\
\hline Sharma et $\mathrm{al}^{37}$ & 63 & 2 & 8 & 57 & 10 & 11 \\
\hline Total & 528 & 453 & 61 & 507 & 561 & 64 \\
\hline \multicolumn{7}{|l|}{ Prospective studies } \\
\hline Vlachogiannakos et a $\mathrm{a}^{42}$ & 23 & NA & 12 & 46 & NA & 58 \\
\hline Irimia et $\mathrm{al}^{40}$ & 66 & NA & 17 & 12 & NA & 4 \\
\hline Total & 89 & NA & 29 & 58 & NA & 62 \\
\hline \multicolumn{7}{|l|}{ Retrospective studies } \\
\hline Mantry and Munsaf ${ }^{46}$ & $65^{*}$ & I & I & $65^{*}$ & 102 & 9 \\
\hline Leevy and Phillips ${ }^{2}$ & $145 *$ & 569 & 10 & $145^{*}$ & 472 & 107 \\
\hline Total & 210 & 570 & 11 & 210 & 574 & 116 \\
\hline
\end{tabular}

Note: *Retrospective design (patients received both treatments consecutively). Abbreviation: NA, not assessed. 
among patients receiving rifaximin. Rifaximin also reduced mortality. Eleven adverse events were registered in the group of patients receiving rifaximin ( $n=23$ patients) and 58 adverse events were registered in the control group ( $n=46$ patients). In an open-label extension of a randomized trial assessing the effect of rifaximin on recurrent HE, 299 patients were included. The duration of therapy was at least 6 months. All patients received rifaximin, including those originally randomized to rifaximin as well as patients originally randomized to placebo. The number of serious adverse events and nonserious adverse events was similar to the placebo period of the randomized trials and did not change with time. ${ }^{43}$

A retrospective study assessed the efficacy of rifaximin in 65 patients. ${ }^{46}$ Charts of patients who were treated with lactulose and subsequently rifaximin were analyzed. The analyses showed that rifaximin reduced the number and duration of hospitalizations due to HE. Furthermore, rifaximin was better tolerated. The number of adverse events associated with rifaximin was scarce or nonexistent and no drug-related serious adverse events were reported in the lactulose or rifaximin treatment period.

Concerns have been raised regarding the long-term treatment with broad-spectrum antibiotics in a vulnerable group of patients. No Clostridium difficile infections were observed in 211 patients receiving rifaximin for more than 6 months. ${ }^{48}$ Stable infection rates during long-term treatment with rifaximin were reported in a prospective cohort study of 392 patients. ${ }^{45}$ However, a prospective study including 283 patients found that proton pump inhibitors, rifaximin, and antibiotics for the prevention of spontaneous bacterial peritonitis were predictors of recurrent infections in patients with cirrhosis. ${ }^{44}$ Another prospective study of 115 infections occurring in 746 patients found that systemic antibiotics, but not oral nonabsorbable antibiotics, were predictors of antibiotic-resistant infections. ${ }^{41}$

\section{Patient acceptability and adherence to treatment with rifaximin}

Randomized trials provide limited information on patient adherence to rifaximin. Two trials have reported mean adherence rates to treatment between $84 \%$ and $92 \% .{ }^{14,15}$ In comparison, a trial on lactulose reported that adherence rates were $54 \% .{ }^{55}$ In a retrospective study, patients received rifaximin and lactulose for a time period of 6 months. The study defined compliance as adherence with at least $75 \%$ of medication. The results showed that $92 \%$ of patients in the rifaximin group and $31 \%$ of patients in the lactulose group were compliant. ${ }^{2}$
Various factors play a part in adherence to medication in cirrhosis and HE. Fatigue and confusion and the lack of social support are likely to have a negative influence on compliance. Complex dosage regimens may also add to the lack of adherence. ${ }^{56}$

\section{Cost-benefit issues}

At this point, no analyses on adherence to self-paid rifaximin are available. For the individual patient, the price of the drug has a substantial impact on adherence. Redeeming prescriptions at the pharmacy depends on economic means. The majority of third-party coverage in the US and other large markets often means that patients pay a smaller outof-pocket copayment rather than the full cost. Although the monthly savings are about US\$100, the costs of rifaximin remain higher than lactulose..$^{20,57}$

Decreased hospitalization rates have been the subject of analyses of cost-efficiency in cirrhosis. A retrospective analysis of 39 patients found that the cost per person per year was lower if patients were treated with rifaximin compared with lactulose. ${ }^{49}$ In contrast, a decision analysis from 2007 found that rifaximin monotherapy was not cost-effective based on the average wholesale prices. Instead, lactulose monotherapy and "rifaximin-salvage therapy," combining rifaximin and lactulose in patients with no initial response to lactulose, proved cost-efficient. ${ }^{52}$ Based on an estimated patient adherence to rifaximin of $95 \%$, a cost-effectiveness analysis on the diagnosis and treatment of minimal HE was performed. The analysis evaluated data regarding the effect of HE on the prevention of motor vehicle accidents. The results showed that rifaximin was not cost-effective unless prices fell to US\$353 per month from the current US\$1,259 per month. ${ }^{20,51}$

Although the costs of rifaximin are much higher than lactulose or lactitol, there seems to be evidence supporting the use of rifaximin to prevent new events of HE hospitalizations due to HE episodes or other complications to cirrhosis. Rifaximin used as rescue therapy may lead to savings on health care costs. ${ }^{53}$ However, the use of rifaximin will in large terms move the economic burden from the health care system to the individual patient. The result may induce greater heterogeneity in outcomes such as mortality and admission rates among patients with cirrhosis and HE. Patients will be divided into those who can afford rifaximin and those who cannot. It has been argued that since Alfa Wassermann S.p.A (Bologna, Italy) holds a patent on rifaximin that expires in 2024, prices are unlikely to decrease before that date. ${ }^{58}$ 


\section{Discussion}

\section{Summary of main results}

The majority of trials and studies on rifaximin have assessed the effects on overt HE. Several trials evaluated shorter treatment regimens lasting only days. The trials have included: patients with acute or chronic recurrent overt HE, transjugular intrahepatic portosystemic shunt patients at risk of developing HE, minimal HE with no previous episodes of HE, as well as HE prevention. Other studies include decision analyses of health care expenses. The trials and studies vary markedly in quality and design. Overall, in spite of these concerns, there seems to be evidence supporting the beneficial effects of rifaximin. Rifaximin may benefit patients with overt $\mathrm{HE}$ and be effective in the prevention of recurrent episodes of HE. Long-term treatment is not associated with an increased risk of adverse events. The risk of Clostridium difficile or other infections may not be increased. However, the evidence is not clear. During recent years, a number of analyses on hospitalization rates have suggested that rifaximin decreases both the number of hospitalizations and the duration of hospital stays. These results suggest that rifaximin may be competitive with lactulose from a socioeconomic perspective. However, the literature cannot address these questions in an exhaustible manner. Prospective and randomized trials with prolonged follow-up are still needed to clarify the beneficial effects of rifaximin in long-term maintenance treatment.

\section{Overall completeness and applicability of evidence}

The effects of long-term treatment with rifaximin are evaluated in a randomized trial that included an extension period of several months. Prospective follow-up of this trial assessed rifaximin treatment for up to 1,400 days. This trial combined with prospective cohort studies and retrospective studies has found reasonable adherence and a small risk of adverse events associated with long-term rifaximin. Unfortunately, there are no randomized trials on hospitalization rates, mortality, complications, and infection rates in long-term rifaximin treatment. Furthermore, the retrospective studies are based on an American population and may not be generalizable to the use and distribution of the drug in the rest of the world. No trials address patient acceptability and adherence in the assessment of main outcomes or the actual use of rifaximin in a clinical setting.

Rifaximin was approved by the US FDA for travelers' diarrhea in 2004. In 2010, rifaximin was approved for HE. A large study on the use of rifaximin in the US found that $12 \%$ of patients with an episode of overt HE received rifaximin either as single treatment (4\%) or in combination with lactulose (8\%). In 2011, this number increased to $22 \%$ (13\% and $9 \%$ respectively). ${ }^{50}$ The clinical use of rifaximin in other parts of the world is not clarified, and compliance to rifaximin as redeemed prescriptions and actual adherence to medication remains unanswered.

\section{Quality of the evidence}

Several limitations apply to this overview, mainly based on the quality of trials, studies, and outcomes. Randomized trials are generally of high quality, but the variation in clinical outcomes impedes assessment and interpretation. In all other questions regarding hospitalization, infections, long-term acceptability, and adherence to medication, we are left with prospective cohorts with or without a control group and retrospective studies that may bias our conclusions.

\section{Agreements and disagreements with other studies or reviews}

Clinical trials and retrospective analyses assessed in this review are the foundation of several reports conducted within the area of treatment and prevention of HE. However, only a few reviews have focused on patient adherence and maintenance therapy. A recent report on minimal HE and prophylactic treatment proposes treatment to prevent not only motor vehicle accidents and quality of life, but also new episodes of overt HE. ${ }^{59}$ Probiotics, disaccharides, and rifaximin are suggested in no prioritized order. Another review suggests disaccharides as first-line treatment in overt HE and minimal $\mathrm{HE}$, and in the case of recurrent HE or no improvement, addition of branched-chain amino acids or rifaximin. ${ }^{60}$ Still, recommendations of long-term treatment are lacking.

\section{Authors' conclusion}

Rifaximin has potential beneficial effects in both overt HE and to prevent recurrent episodes of HE. Additional evidence is needed to determine the effects of rifaximin in clinical practice. In particular, the evidence supporting the use of rifaximin for minimal HE is weak. Knowledge about longterm maintenance treatment is scarce. The current cost of the drug may very well influence both the duration of treatment and adherence to medication.

\section{Implications for practice}

Rifaximin should be considered after the second episode of overt HE as well as during episodes of overt HE for patients who do not respond to standard treatment. Whether the treatment is second- or third-line after disaccharides and branched-chain amino acids has not been established. 
Likewise, additional evidence on the combination of these treatments is needed. The current literature does not clearly support rifaximin being given continuously on a lifelong basis; due to this and the extensive cost of the drug, discontinuation ought to be considered in relation to the patients' health and risk of complications.

\section{Implications for research}

This review identifies unresolved areas. Most importantly, data on patient adherence to prescribed medicine is needed. Secondly, the safety of prolonged treatment must be mapped out to improve our understanding of the risks and benefits of maintenance treatment. Clinical trials on rifaximin are conducted, but randomized trials or prospective controlled trials with clinical outcome measures such as mortality, complication rates, patient compliance, and adverse events, in a prolonged treatment design, are warranted.

\section{Author contributions}

Nina Kimer performed the literature searches, extracted data, and wrote the draft for this review; Aleksander Krag and Lise L Gluud validated the data extraction and contributed to the revision of the review. All authors approved the final version.

\section{Disclosure}

Lise L Gluud and Aleksander Krag report no conflicts of interest in the work. Nina Kimer has received rifaximin tablets and placebo from Norgine Denmark A/S in relation to an ongoing trial.

\section{References}

1. Jepsen P, Ott P, Andersen PK, Sorensen HT, Vilstrup H. Clinical course of alcoholic liver cirrhosis: a Danish population-based cohort study. Hepatology. 2010;51(5):1675-1682.

2. Leevy CB, Phillips JA. Hospitalizations during the use of rifaximin versus lactulose for the treatment of hepatic encephalopathy. Dig Dis Sci. 2007;52(3):737-741.

3. Poordad FF. Review article: the burden of hepatic encephalopathy. Aliment Pharmacol Ther. 2007;25 Suppl 1:3-9.

4. Ferenci P, Lockwood A, Mullen K, Tarter R, Weissenborn K, Blei AT. Hepatic encephalopathy - definition, nomenclature, diagnosis, and quantification: final report of the working party at the 11th World Congresses of Gastroenterology, Vienna, 1998. Hepatology. 2002;35(3): $716-721$.

5. Cordoba J. New assessment of hepatic encephalopathy. J Hepatol. 2011;54(5):1030-1040.

6. Bajaj JS, Cordoba J, Mullen KD, et al. Review article: the design of clinical trials in hepatic encephalopathy - an International Society for Hepatic Encephalopathy and Nitrogen Metabolism (ISHEN) consensus statement. Aliment Pharmacol Ther. 2011;33(7):739-747.

7. Mardini H, Record C. Pathogenesis of hepatic encephalopathy: lessons from nitrogen challenges in man. Metab Brain Dis. 2013;28(2): 201-207.

8. Bajaj JS. Review article: the modern management of hepatic encephalopathy. Aliment Pharmacol Ther. 2010;31(5):537-547.
9. Prakash R, Mullen KD. Mechanisms, diagnosis and management of hepatic encephalopathy. Nat Rev Gastroenterol Hepatol. 2010;7(9): 515-525.

10. Riordan SM, Williams R. Gut flora and hepatic encephalopathy in patients with cirrhosis. $N$ Engl J Med. 2010;362(12):1140-1142.

11. Phongsamran PV, Kim JW, Cupo Abbott J, RosenblattA. Pharmacotherapy for hepatic encephalopathy. Drugs. 2010;70(9):1131-1148.

12. Scarpignato C, Pelosini I. Rifaximin, a poorly absorbed antibiotic: pharmacology and clinical potential. Chemotherapy. 2005; 51 Suppl 1: 36-66.

13. Bajaj JS, Heuman DM, Sanyal AJ, et al. Modulation of the metabiome by rifaximin in patients with cirrhosis and minimal hepatic encephalopathy. PloS One. 2013;8(4):e60042.

14. Bajaj JS, Heuman DM, Wade JB, et al. Rifaximin improves driving simulator performance in a randomized trial of patients with minimal hepatic encephalopathy. Gastroenterology. 2011;140(2): 478-487. e471.

15. Bass NM, Mullen KD, Sanyal A, et al. Rifaximin treatment in hepatic encephalopathy. N Engl J Med. 2010;362(12):1071-1081.

16. Bucci L, Palmieri GC. Double-blind, double-dummy comparison between treatment with rifaximin and lactulose in patients with medium to severe degree hepatic encephalopathy. Curr Med Res Opin. 1993;13(2):109-118.

17. De Marco F, Santamaria Amato P, D'Arienzo A. Rifaximin in collateral treatment of portal-systemic encephalopathy: a preliminary report. Curr Ther Res. 1984;36(4):668-674.

18. Mas A, Rodes J, Sunyer L, et al. Comparison of rifaximin and lactitol in the treatment of acute hepatic encephalopathy: results of a randomized, double-blind, double-dummy, controlled clinical trial. J Hepatol. 2003;38(1):51-58.

19. Parini PCA, Ronchi M, Salzetta A, Mazella G, Roda E. Effect of rifaximin and paromycin in the treatment of portal-systemic encephalopathy. Curr Ther Res. 1992;52(1):34-39.

20. PharmacyChecker [homepage on the Internet]. Available from: http://www.pharmacychecker.com/compare-drug-prices-onlinepharmacies/rifaximin-550+mg/79995/197553/. Accessed February $1,2014$.

21. Neff G. Pharmacoeconomics of hepatic encephalopathy. Pharmacotherapy. 2010;30(5 Pt 2):28S-32S.

22. Di Piazza S, Gabriella Filippazzo M, Valenza LM, et al. Rifaximine versus neomycin in the treatment of portosystemic encephalopathy. Ital J Gastroenterol. 1991;23(7):403-407.

23. Eftimiadi C, Deleo C, Schito GC. Treatment of hepatic encephalopathy with L/105, a new non-absorbable rifamycin. Drugs Exp Clin Res. 1984;10:691-696.

24. Riggio O, Masini A, Efrati C, et al. Pharmacological prophylaxis of hepatic encephalopathy after transjugular intrahepatic portosystemic shunt: a randomized controlled study. J Hepatol. 2005;42(5): 674-679.

25. Song KH LK, Kim MH, Paik YH, et al. The clinical efficacy of rifaximin in the treatment of hepatic encephalopathy (comparison with lactulose). Hepatology. 2000;32(4):407A.

26. Testa R, Eftimiadi C, Sukkar GS, et al. A non-absorbable rifamycin for treatment of hepatic encephalopathy. Drugs Exp Clin Res. 1985;11(6): 387-392.

27. Venturini I, Ferrieri A, Farina F, et al. Evaluation of rifaximin, placebo and lactulose in reducing the levels of benzodiazepine-like compounds in patients with liver cirrhosis: a pilot study. Drugs Exp Clin Res. 2005;31(4):161-168.

28. Williams R, James OF, Warnes TW, Morgan MY. Evaluation of the efficacy and safety of rifaximin in the treatment of hepatic encephalopathy: a double-blind, randomized, dose-finding multi-centre study. Eur J Gastroenterol Hepatol. 2000;12(2):203-208.

29. Bass NM, Ahmed A, Johnson L, Gardner JD. Rifaximin treatment is beneficial for mild hepatic encephalopathy. Hepatology. 2004;40:646A (abstract).

30. Fera GFA, Nigro M, Schiraldi O, Ferrieri A. Rifaximin in the treatment of hepatic encephalopathy. Eur J Clin Res. 1993;4:57-66. 
31. Festi D, Mazzella G, Orsini M, et al. Rifaximin in the treatment of chronic hepatic encephalopathy: results of a multicenter study of efficacy and safety. Curr Ther Res. 1993;54(5):598-609.

32. Loguercio C, Federico A, De Girolamo V, Ferrieri A, Del Vecchio Blanco C. Cyclic treatment of chronic hepatic encephalopathy with rifaximin. Results of a double-blind clinical study. Minerva Gastroenterol Dietol. 2003;49(1):53-62.

33. Massa PVF, Dodero M. Treatment of hepatic encephalopathy with rifaximin. Eur J Clin Res. 1993;4:7-18.

34. Miglio F, Valpiani D, Rossellini SR, Ferrieri A. Rifaximin, a nonabsorbable rifamycin, for the treatment of hepatic encephalopathy. A double-blind, randomised trial. Curr Med Res Opin. 1997;13(10): 593-601.

35. Paik YH, Lee KS, Han KH, et al. Comparison of rifaximin and lactulose for the treatment of hepatic encephalopathy: a prospective randomized study. Yonsei Med J. 2005;46(3):399-407.

36. Pedretti G, Calzetti C, Missale G, Fiaccadori F. Rifaximin versus neomycin on hyperammoniemia in chronic portal systemic encephalopathy of cirrhotics. A double-blind, randomized trial. Ital $J$ Gastroenterol. 1991;23(4):175-178.

37. Sharma BC, Sharma P, Lunia MK, Srivastava S, Goyal R, Sarin SK. A randomized, double-blind, controlled trial comparing rifaximin plus lactulose with lactulose alone in treatment of overt hepatic encephalopathy. Am J Gastroenterol. 2013;108(9):1458-1463.

38. Sidhu SS, Goyal O, Mishra BP, Sood A, Chhina RS, Soni RK. Rifaximin improves psychometric performance and health-related quality of life in patients with minimal hepatic encephalopathy (the RIME Trial). Am J Gastroenterol. 2011;106(2):307-316.

39. Sanyal A, Younossi ZM, Bass NM, et al. Randomised clinical trial: rifaximin improves health-related quality of life in cirrhotic patients with hepatic encephalopathy - a double-blind placebo-controlled study. Aliment Pharmacol Ther. 2011;34(8):853-861.

40. Irima R, Trifan A. Efficacy of rifaximin versus lactulose for reducing the recurrence of overt hepatic encephalopathy and hospitalizations in cirrhosis. Rev Med Chir Soc Med Nat Iasi. 2012;116(4):1021-1027.

41. Tandon P, Delisle A, Topal JE, Garcia-Tsao G. High prevalence of antibiotic-resistant bacterial infections among patients with cirrhosis at a US liver center. Clin Gastroenterol Hepatol. 2012;10(11):1291-1298.

42. Vlachogiannakos J, Viazis N, Vasianopoulou P, Vafiadis I, Karamanolis DG, Ladas SD. Long-term administration of rifaximin improves the prognosis of patients with decompensated alcoholic cirrhosis. J Gastroenterol Hepatol. 2013;28(3):450-455.

43. Bajaj JBE, Paterson C, Forbes WP. Long-term use of rifaximin is associated with reduced hospitalizations, prolonged remission: a placebo crossover analysis. Hepatology. 2012;56(Suppl 4):925A-926A.

44. O'Leary JG, Reddy KR, Wong F, et al. Long-term antibiotic and protonpump inhibitor use are strong predictors of recurrent infections in cirrhosis: a prospective multi-center study from NACSELD. J Hepatol. 2013;58(Suppl 1):S97.
45. Sanyal AMK, Bass NM, Frederick T, et al. Rates of commonly occurring infections in cirrhosis patients remain stable during long-term rifaximin treatment. J Hepatol. 2012;56(Suppl 1):S255-S256.

46. Mantry PS, Munsaf S. Rifaximin for the treatment of hepatic encephalopathy. Transplant Proc. 2010;42(10):4543-4547.

47. Neff GW, Jones M, Broda T, et al. Durability of rifaximin response in hepatic encephalopathy. J Clin Gastroenterol. 2012;46(2):168-171.

48. Neff GW, Jones M, Jonas M, et al. Lack of Clostridium difficile infection in patients treated with rifaximin for hepatic encephalopathy: a retrospective analysis. J Clin Gastroenterol. 2013;47(2): $188-192$.

49. Neff GW, Kemmer N, Zacharias VC, et al. Analysis of hospitalizations comparing rifaximin versus lactulose in the management of hepatic encephalopathy. Transplant Proc. 2006;38(10):3552-3555.

50. Neff GW. Assessing treatment patterns in patients with overt hepatic encephalopathy. Hepatology. 2012;56(Suppl 4):945A.

51. Bajaj JS, Pinkerton SD, Sanyal AJ, Heuman DM. Diagnosis and treatment of minimal hepatic encephalopathy to prevent motor vehicle accidents: a cost-effectiveness analysis. Hepatology. 2012;55(4):1164-1171.

52. Huang E, Esrailian E, Spiegel BM. The cost-effectiveness and budget impact of competing therapies in hepatic encephalopathy - a decision analysis. Aliment Pharmacol Ther. 2007;26(8):1147-1161.

53. Neff GW, Kemmer N, Duncan C, Alsina A. Update on the management of cirrhosis - focus on cost-effective preventative strategies. Clinicoecon Outcomes Res. 2013;5:143-152.

54. Sharma BC, Sharma P, Agrawal A, Sarin SK. Secondary prophylaxis of hepatic encephalopathy: an open-label randomized controlled trial of lactulose versus placebo. Gastroenterology. 2009;137(3):885-891, 891. e1.

55. Bajaj JS, Sanyal AJ, Bell D, Gilles H, Heuman DM. Predictors of the recurrence of hepatic encephalopathy in lactulose-treated patients. Aliment Pharmacol Ther. 2010;31(9):1012-1017.

56. Neff G. Factors affecting compliance and persistence with treatment for hepatic encephalopathy. Pharmacotherapy. 2010;30(5 Pt 2): 22S-27S.

57. Chemistdirect.co.uk [homepage on the Internet]. Lactulose solution. Oldbury, UK: Chemist Direct. Available from: http://www. chemistdirect.co.uk/lactulose-solution_1_10158.html\#10158. Accessed January 9, 2014.

58. Drugs.com [homepage on the Internet]. Xifaxan. Available from: http:// www.drugs.com/xifaxan.html. Accessed January 9, 2014.

59. Prakash RK, Kanna S, Mullen KD. Evolving concepts: the negative effect of minimal hepatic encephalopathy and role for prophylaxis in patients with cirrhosis. Clin Ther. 2013;35(9):1458-1473.

60. Gluud LL, Dam G, Borre M, et al. Lactulose, rifaximin or branched chain amino acids for hepatic encephalopathy: what is the evidence? Metab Brain Dis. 2013;28(2):221-225.
Patient Preference and Adherence

\section{Publish your work in this journal}

Patient Preference and Adherence is an international, peer-reviewed, open access journal focusing on the growing importance of patient preference and adherence throughout the therapeutic continuum. Patient satisfaction, acceptability, quality of life, compliance, persistence and their role in developing new therapeutic modalities and compounds to
Dovepress

optimize clinical outcomes for existing disease states are major areas of interest. This journal has been accepted for indexing on PubMed Central. The manuscript management system is completely online and includes a very quick and fair peer-review system. Visit http://www.dovepress.com/ testimonials.php to read real quotes from published authors. 